\title{
The Impact of Psychological Distance on Judging Satisfaction with Nuclear Energy Policy via Knowledge Calibration and an Integrated Causal Path Model
}

\author{
Byoung Joon Kim ${ }^{1}$ and Seoyong Kim $^{2, *(D)}$ \\ 1 Department of Public Administration, Kookmin University, Seoul 02707, Korea; kimbj@kookmin.ac.kr \\ 2 Department of Public Administration, Ajou University, Suwon 16499, Korea \\ * Correspondence: seoyongkim@ajou.ac.kr
}

check for updates

Citation: Kim, B.J.; Kim, S. The Impact of Psychological Distance on Judging Satisfaction with Nuclear Energy Policy via Knowledge Calibration and an Integrated Causal Path Model. Energies 2021, 14, 5774. https://doi.org/10.3390/en14185774

Academic Editor: T M Indra Mahlia

Received: 24 July 2021

Accepted: 8 September 2021

Published: 13 September 2021

Publisher's Note: MDPI stays neutral with regard to jurisdictional claims in published maps and institutional affiliations.

Copyright: (c) 2021 by the authors. Licensee MDPI, Basel, Switzerland. This article is an open access article distributed under the terms and conditions of the Creative Commons Attribution (CC BY) license (https:// creativecommons.org/licenses/by/ $4.0 /)$.

\begin{abstract}
This study investigated how, through knowledge calibration and a causal path model, psychological distance can explain the level of satisfaction with nuclear energy policy. The investigation used multiple regression analysis and path analysis to explore relationships among variables. Data from 1056 adults revealed that more knowledge-calibrated individuals have more positive attitudes toward nuclear energy policy. In addition, the psychological distance influences policy satisfaction by mediation of perceived risk of nuclear energy. This study aimed to increase the understanding of the dynamic of satisfaction with and acceptance of nuclear energy policy among stakeholders. Thus, based on the construal level theory, the study addressed the importance of knowledge and psychological distance in explaining variation in satisfaction and acceptance about nuclear policy.
\end{abstract}

Keywords: psychological distance; policy satisfaction; knowledge calibration; risk perception; nuclear energy policy

\section{Introduction}

Following Japan's Fukushima nuclear accident in March 2011, the public's acceptance level of nuclear energy decreased dramatically, as did the trust in nuclear policy [1]. However, gaps still exist between the scientifically explained level of objective risk and people's subjective beliefs and attitudes about the risk [2]. Previous studies have explored a number of variables that could influence nuclear energy policy's risk perception, satisfaction, and compliance (e.g., Tanaka [3]; Flynn et al. [4]; Visschers and Siegrist [5]), possibly including the level of perceived risk, perceived benefits, trust, knowledge, feelings, and experiences [6]). Thus, this study introduces two exploratory investigations.

First, this investigation relies on a current focal point in social psychology, i.e., the psychological distance (PD) of construal level theory. PD refers to the subjective experience of something as near or far from others, including other persons, events, time periods, and hypotheticality [7]. Liberman and Trope [7] insisted that PD is a subjective, egocentric concept and categorized it as temporal, spatial, social, and hypothetical [8]. For instance, people see distant mountains as beautiful and evaluate them generously as they cannot perceive any flaws. Up close, however, people can see disarray and mess, so their judgment is frequently more punitive. Thus, PD might influence overall satisfaction and acceptance (SA). In addition, the relationship between PD and SA depends both on accurate knowledge, in this case, of nuclear power, and the level of confidence in that knowledge.

A number of studies have been conducted on determinants of SA, but PD and knowledge calibration $(\mathrm{KC})$ have not been considered seriously or separately. In addition, other psychological factors were not investigated along with these factors. Therefore, this paper is an exploratory study over them.

In previous studies about satisfaction with nuclear energy policy, individuals' perceptions have been determinant, and their behaviors were outcomes of rational motivation. 
This study investigates how a theory on PD might meaningfully explain individuals' judging process in nuclear issues. Moreover, nuclear energy policy issues could be strongly influenced by individuals' risk perception and level of knowledge. Thus, this study emphasizes the theoretical causal model. From this study, public policymakers can learn how to provide public information that contributes to appropriate calibration of citizens' knowledge about nuclear energy policies.

Second, PD could play a critical role in the combination path model among the expectancy disconfirmation model (EDM), risk perception, and trust in government. According to Jeon et al. [9], a positive disconfirmation between expectation and performance of nuclear power energy policy increased trust in government and acceptance of nuclear policy. Moreover, when individual citizens' risk perception increased, their acceptance decreased. Therefore, this study purports to discover PD's role in the model and to introduce a new instrument with a new approach, providing a novel viewpoint of citizens' policy satisfaction with and acceptance of the nuclear energy policy.

The next section reviews related studies and displays the research model and hypotheses. The section after that reports survey data and methods. Then, to expand our knowledge in this new field, results of two preliminary empirical studies are reported. The final section discusses implications and limitations for developing empirical models.

\section{Theoretical Background and Hypotheses}

\subsection{Study 1: Knowledge Calibration (KC) with Psychosocial Distance (PD) on Nuclear Energy} Policy Satisfaction (PS)

Research studies on nuclear energy has focused mainly on how knowledge has improved acceptance of it among citizens [10]. For instance, some previous studies have shown that increased knowledge of nuclear energy reduced perceived risk and increased public acceptance. In contrast, some research with somewhat different results show insignificant relations between levels of risk and simultaneous policy acceptance [11-13].

However, referring to research on nuclear energy policy using KC with PD is difficult because of very few studies. Goldsmith and Pillai [14,15] defined KC as correspondence between knowledge's accuracy and the confidence with which the knowledge is held. Calibration is a potentially important concept for knowledge management because it describes one of the subtle errors that can lead to poor decisions $[14,15]$. For consumers, calibration is important in decision making because it allows them to cope with incomplete and erroneous information [16]. However, calibrating such knowledge is not an easy task. After reviewing a wide variety of empirical results, Alba and Hutchinson [16] showed that high levels of calibration are rarely achieved, moderate levels including some degree of systematic bias are the norm, and confidence and accuracy are sometimes completely uncorrelated.

Knowledge is related not only to nuclear power's acceptability, but also to various causal variables (e.g., perceived risk, perceived benefit, trust, knowledge, emotion) that determine its acceptability. Thus, previous studies have revealed that knowledge positively enhances acceptance of nuclear power [12,17-19]. In general, however, the public does not have good understanding of nuclear power risks due to lack of knowledge about its plants, not because the public is ignorant, but because the information they receive is incomplete [18].

Functionally, knowledge directly or indirectly affects acceptance of nuclear power. Those with much knowledge about radiation tend to underestimate the level of risk associated with nuclear power [20]. In addition, people with a high level of knowledge about nuclear power tend to judge risk based on their perception of risk and the amount of electricity produced. Moreover, as knowledge about a particular risk increases, people become less reliant on trust [21]. Knowledge also moderates the effect of psychometric paradigm variables such as trust, perceived benefit, and stigma on acceptance of nuclear power [22-24]. Type of knowledge is also important because subjective knowledge performs more important function than objective knowledge [25]. Park and Kim [10] 
showed that in judging nuclear energy, subjective and objective knowledge increases and psychometric variables were identified as forces mitigating the risk perception.

As for PD's functional role, high psychological distance produces more general and abstract internal representations of the object, while low psychological distance raises more concrete and contextual conceptualizations. This degree of PD's proximity and specificity is linked to the receptivity of the specific object concerned [26]. For example, Liu et al. [27] demonstrated that when risk perception of air pollution's consequences plays a considerable mediating role in inducing purchase intention for new energy vehicles, consumers' PD toward air pollution has a significant effect. Furthermore, Tan et al. [28] showed that different dimensions of PD (e.g., social, temporal, uncertainty, and experiential) might explain local acceptance of shale gas development in China. $\mathrm{Ng}$ et al. [29] revealed that cultural similarity and spatial distance has a kind of distance that influences a tourist's intention to visit a country.

These research results suggest that PD is related to a specific risky object's acceptability. So, which factors affect PD? Methods to reduce PD depend on knowledge of a specific object. According to Ankomach et al. [30], cognitive distance is given not only by external information (socio-cultural differences) but also by internal information (knowledge and memory). Moreover, McKay and Fesenmayer [31] showed that high familiarity with a place correlates with affect, i.e., a more realistic image of the place. Moreover, acquisition of information without activation of a stereotype reduces social distance [32].

From the discussion above, a tentative hypothesis can be drawn that KC plays a role in regulating the relationship between PD and policy acceptance and satisfaction.

Therefore, in this study, we conducted a policy satisfaction (PS) study by applying the concept of KC with PD. Participants $(n=1056)$ answered 10 questions related to knowledge of nuclear energy. Afterward, they ranked their level of belief about how many of their answers were correct and provided their 'level of confidence' about that score. The level of $\mathrm{KC}$ on nuclear energy is calculated based on differences between the numbers of questions participants believe they answered correctly and how many answers were actually correct (the level of accuracy). The gap between level of confidence and accuracy produces a $2 \times 2$ table [15], which displays four groups (See Table 1). First, the over miscalibrated group shows high gaps between actual scores and level of confidence $(n=333)$. This condition is "overconfidence." Second are high calibrated scores, meaning that expected scores and real scores exactly match and are high. This condition is "high just calibration" $(n=122)$. Third is "low just calibration," which is like the second condition but matching accurately in lower scores $(n=186)$. Finally, there are "under miscalibration" or "under confidence," which means high accuracy but lower confidence $(n=425)$.

Table 1. Calibration of accuracy, confidence, and knowledge.

\begin{tabular}{clll}
\hline & High & $\begin{array}{l}\text { (1) Over } \\
\text { miscalibration or } \\
\text { overconfidence } \\
(n=333)\end{array}$ & $\begin{array}{l}\text { (2) High just } \\
\text { calibration } \\
(n=112)\end{array}$ \\
\cline { 2 - 4 } Confidence & Low & $\begin{array}{l}\text { (3) Low just } \\
\text { calibration } \\
(n=186)\end{array}$ & $\begin{array}{l}\text { (4) Under } \\
\text { miscalibration or } \\
\text { under confidence } \\
(n=425)\end{array}$ \\
\cline { 3 - 4 } & \multicolumn{2}{c}{ Low High } \\
\hline
\end{tabular}

Examining the effects of PD on PS with KC requires developing a statistical model that addresses a series of multiple regression analyses to compare standardized coefficient $\beta \mathrm{s}$ of four models: (1) High Just Calibration, (2) Low Just Calibration, (3) Under Confidence, and (4) Over Confidence. The hypotheses of the first examination are as follows. 
Hypothesis 1 (H1). Under four types of KC, PD shows different relationships with PS when age, gender, education, and income are controlled.

2.2. Study 2: The Impact of PD on PS and Policy Acceptance (PA) through Trust in Government (TG), Policy Expectance Disconfirmation (PED), and Risk Perception (RP)

Previous studies on PS and policy acceptance (PA) have adopted and emphasized different independent variables. In marketing research, $\mathrm{PD}$ and satisfaction are emphasized; in government service research, trust in government (TG) is emphasized; and in risk research, risk perception (RP) is emphasized. By integrating these different theoretical models $[2-4,14,15]$ as in Figure 1, this study analyzes effects of PD, PED, TG, and RP on PS and PA.

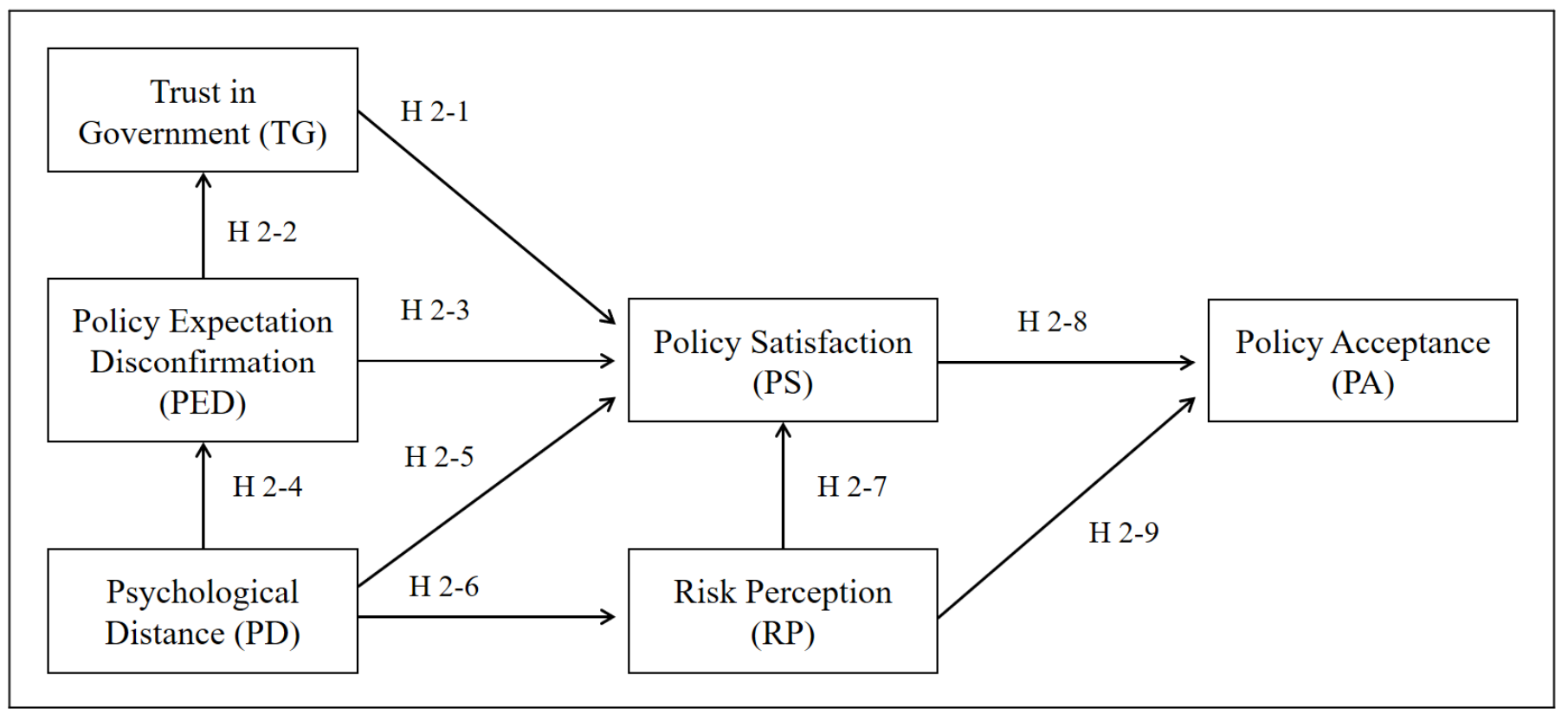

Figure 1. Proposed research model.

Considering the model's six variables, the proposed path model (Figure 1) postulates nine hypotheses. First, trust is a key variable in PS. Previous studies have conceptualized trust as a product of a citizen's preference regarding either policy or electoral outcomes [33]. Trust is simply one factor developed to understand the public's confidence in government. Some leading scholars have linked declining TG to declining political participation [34], and many consider it no accident that the dramatic decline in turnout rates in the United States since the 1960s mirrors a decline in political trust [33]. Furthermore, in studies on nuclear energy policy, levels of TG have correlated positively with level of PS [35]. Additionally, Lægreid and Christensen [36] showed that citizens satisfied with specific public services generally have a higher level of trust in public institutions than dissatisfied citizens.

Hypothesis 2-1 (H2-1). TG is positively associated with PS.

Furthermore, Oliver [37] showed that expectation and disconfirmation are key variables in determining satisfaction. Oliver [37] argued that, in marketing research, customers show higher satisfaction when their expectations and real performance are just met or when the level of real performance is higher than expected, that is "positive inconsistencies with higher expectations but low performance". Therefore, judgments on satisfaction are determined not just by product or service performance but by a process in which consumers compare performance with their prior expectations [38]. Meanwhile, if customers' expectations are higher than performance, this is referred to as "negative inconsistencies 
with higher performance but low expectation". According to the EDM, service satisfaction is decided by expectation and performance [39].

Moreover, the EDM can be applied to nuclear energy policy. Jeon et al. [9] found policy expectation disconfirmation positively associated not only with TG but also with PS. Thus, citizens' disconfirmation of expectations is a main determinant of citizen satisfaction $[38,39]$.

Hypothesis 2-2 (H2-2). PED is positively associated with TG.

Hypothesis 2-3 (H2-3). PED is positively associated with PS.

Maglio [40] (p. 108) explained that seeing something as psychologically distant causes people to think about and act on it in systematically different ways more than on the same thing seen as psychologically close. In market studies, PD critically influences customers' behavior including expectation and satisfaction. For example, Darke et al. [41] showed that distance felt by consumers impedes their trust in and willingness to purchase from online retailers. In contrast, service providers spark greater customer satisfaction and future purchases when they respond to customers by personifying themselves as " $\mathrm{I}^{\text {" (making }}$ themselves, and, in turn, the firm seem socially closer) instead of as the socially distant, firm-level collective "we" [42]. Moreover, Zheng [43] demonstrated that PD mediated relationships between regional pandemic severity and perceived general satisfaction.

Hypothesis 2-4 (H2-4). PD is positively associated with PED.

Hypothesis 2-5 (H2-5). PD is positively associated with PS.

Lower PD generally was related to higher levels of RP. Spence et al. [44] showed that perceived impacts on developing countries, as an indicator of social distance, related significantly to preparedness for climate change action. Chu and Yang [45] demonstrated that PD influences the effect of risk versus efficacy framing on climate change engagement. In particular, under further PD, risk framing increased behavioral intention through heightened RP. This implies that RP can play a moderating role in specific kinds of PD. Therefore, we tested how PD can influence the level of RP.

Hypothesis 2-6 (H2-6). PD is positively associated with RP.

According to Kim [46], risk information about nuclear energy influences the public. In other words, depending on how individuals perceive risk level, PS and acceptance change. A higher level of perceived risk brings lower a level of SA of nuclear energy policypossibly closely related with risk characteristics and risk information attributes [47].

$\mathrm{RP}$ is a key factor influencing citizens' satisfaction. During the COVID-19 pandemic, people's satisfaction has been closely related to risk factors such as confirmed cases and deaths per million [48]. In contrast, according to Liu et al. [27], consumers' RP of air pollution's consequences mediates between PD and intended action as a kind of acceptance.

Hypothesis 2-7 (H2-7). RP is negatively associated with PS.

Hypothesis 2-8 (H2-8). RP is negatively associated with PA.

In our suggested model, PA is a policy implementation outcome for customers who evaluate the quality of services and products. PA refers to judgments about and evaluations of the policy in place [49]. Generally, acceptance is expected to be strongly influenced by the satisfaction and citizens' experience when receiving service from a government or company.

Hypothesis 2-9 (H2-9). PS is positively associated with PA. 


\section{Materials and Methods}

This study's data was collected in June 2015 from surveys of citizens living in South Korea. The online survey (structured questionnaire) "nuclear power policy survey for the public" measured, for example, PD, knowledge correction, and PS related to nuclear energy policy. Adult men and women aged 19 to 59 years old responded through an online panel survey $(n=1056$; response rate $=17.3 \%)$.

On the survey, PA and PS each consisted of five questions ranked on a five-point Likert scale. PA questions included: (1) How much do you think nuclear energy is necessary? (2) How much do you agree that nuclear energy is more important than other energy resources? (3) How much do you agree that nuclear energy should be expanded; (4) How much do you agree with not in my back yard (NIMBY)? (5) How much can you accept nuclear power? PS questions included: How satisfied are you with nuclear energy in terms of (1) safety, (2) usability, (3) economics, (4) environment, and (5) overall. All indicators of the two dependent variables were subjected to reliability analysis. Internal consistency reliability indices were Cronbach $\alpha=0.878$ and 0.899 , respectively

Internal consistency reliability of all items was calculated: PD (20 questions, Cronbach $\alpha=0.866$ ), PED (two questions, Cronbach $\alpha=0.849$ ), TG (five questions, Cronbach $\alpha=0.923$ ), and RP (three questions, Cronbach $\alpha=0.832$ ). Answers to these questions were combined into an additive construct. (Details of survey questions are available upon request)

\section{Results}

\subsection{Findings from Study 1}

Multiple regression models can provide relatively more accurate measures of KC's impact between PD and PS. The first investigation analyzed based on the following model under four regressions that include four types of $\mathrm{KC}$ :

$$
\mathrm{PS}=\beta 0+\beta 1(\mathrm{PD})+\beta 2(\text { Age })+\beta 3(\text { Gender })+\beta 4(\text { Education })+\beta 5(\text { Income })+\varepsilon
$$

Table 2 shows multiple regression results on the independent variable and control variables. In each regression model, the range of coefficient of determination was from $58.6 \%$ to $59.8 \%$, indicating the models to be significant (F-values $=1555.537$ to $15,677.766$; $p<0.001)$. In all four models, PDs were statistically significant, and results provided support for H1. Additionally, more calibrated citizens had stronger positive association between PD and PS. This means that people from the overconfidence group could be more critical of nuclear energy policy, and it shows why micro-targeting the public via public education is more important than ever before.

Table 2. Results of multiple regression analyses.

\begin{tabular}{ccccc}
\hline Model & $\begin{array}{c}\text { Model 1: High Just } \\
\text { Calibration }\end{array}$ & $\begin{array}{c}\text { Model 2: Low Just } \\
\text { Calibration }\end{array}$ & $\begin{array}{c}\text { Model 3: Under } \\
\text { Confidence }\end{array}$ & $\begin{array}{c}\text { Model 4: Over } \\
\text { Confidence }\end{array}$ \\
\cline { 2 - 4 } & \multicolumn{4}{c}{ Standardized Coefficient: Beta } \\
(Constant) & $0.870^{* *}$ & $0.779 *$ & $0.738^{* *}$ & $0.734^{* *}$ \\
Psychological Distance (PD) & 0.145 & -0.071 & 0.043 & -0.098 \\
Age & -0.182 & -0.005 & -0.026 & -0.004 \\
Gender & -0.073 & 0.033 & 0.000 & -0.031 \\
Education & 0.038 & 0.068 & -0.040 & 0.028 \\
Income & &
\end{tabular}

${ }^{*} p<0.05,{ }^{* *} p<0.01,{ }^{* * *} p<0.001$.

\subsection{Findings from Studies 2}

The hypothesized path model to be tested in the second investigation included variables that are linear, additive, and fully recursive in their relationships. In addition, variables in the path model were not correlated with residuals and were measured on a 
5-point Likert scale (interval scale) with good reliability, as mentioned above. Path analysis was performed with IBM SPSS AMOS (IBM, Armonk, NY, USA). Covariance matrices and the maximum likelihood estimation method were conducted to estimate model parameters. Based on Hu and Bentler's [50] guidelines for assessment of overall model fit, the model provided good fit to data (see Table 2$), \chi^{2}(6, n=1037)=69.986, p<0.001$, CFI $=0.968$, AGFI $=0.925$. PD was positively associated with RP $(\beta=0.304, p<0.001)$, but not with PS and policy expectancy disconfirmation (PED). (see Table 3 ).

Table 3. Model fit summary.

\begin{tabular}{cccccccccc}
\hline Model & CMIN & DF & CMIN/DF & RMR & GFI & AGFI & IFI & TLI & CFI \\
\hline Unconstrained & 69.986 & 6 & 11.664 & 0.077 & 0.978 & 0.925 & 0.968 & 0.919 & 0.968 \\
\hline
\end{tabular}

Citizens' PED level was positively associated with TG $(\beta=0.607, p<0.001)$ and PS $(\beta=0.332, p<0.001)$. TG was positively associated with PS $(\beta=0.337, p<0.001)$. RP was negatively associated with PS $(\beta=-0.085, p<0.001)$ and PA $(\beta=-0.274, p<0.001)$. PS was positively associated with PA $(\beta=0.654, p<0.001)$. PD had significantly positive influence on RP, and RP had negative influences on both PS and PA. Interestingly, TG mediated between PED and PS. The link between PD and RP also provided meaningful insight. More details are presented in Figure 2 and Table 4.

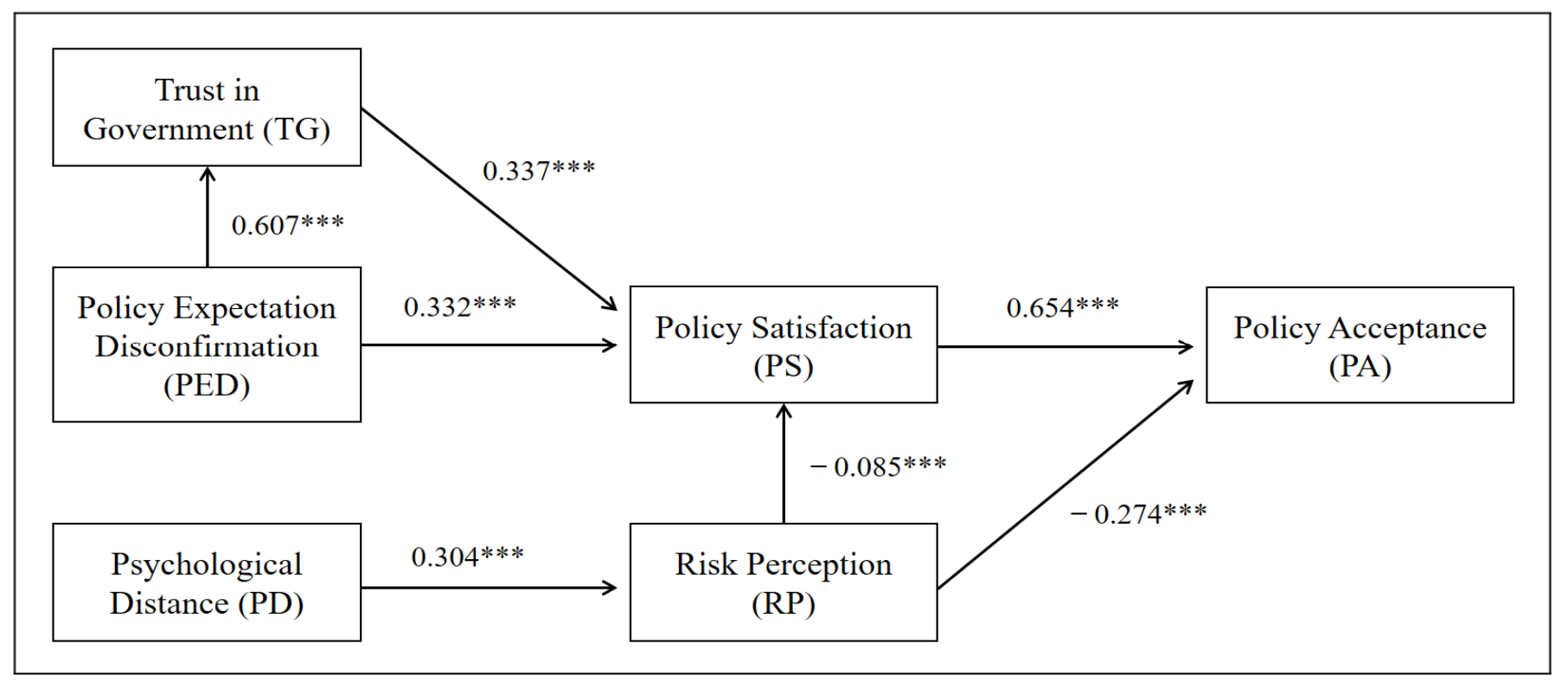

Figure 2. Validated research model (Note: ${ }^{*} p<0.05,{ }^{* *} p<0.01,{ }^{* * *} p<0.001$ ).

Table 4. Results of path analysis.

\begin{tabular}{cccccccc}
\hline Variable 1 & & Variable 2 & Estimate & S.E. & C.R. & $p$ & Label \\
\hline PED & $\leftarrow$ & PD & -0.002 & 0.031 & -0.067 & 0.946 & G1_PD>ED \\
RP & $\leftarrow$ & PD & $\mathbf{0 . 3 0 4}$ & 0.03 & 10.281 & $* * *$ & G1_PD>RP \\
TG & $\leftarrow$ & PED & $\mathbf{0 . 6 0 7}$ & 0.025 & 24.582 & $* * *$ & G1_ED>T \\
PS & $\leftarrow$ & TG & $\mathbf{0 . 3 3 7}$ & 0.031 & 10.859 & $* * *$ & G1_T>S \\
PS & $\leftarrow$ & PED & $\mathbf{0 . 3 3 2}$ & 0.031 & 10.683 & $* * *$ & G1_ED>S \\
PS & $\leftarrow$ & PD & -0.029 & 0.026 & -1.106 & 0.269 & G1_PD $>$ S \\
PS & $\leftarrow$ & RP & $-\mathbf{0 . 0 8 5}$ & 0.026 & -3.262 & $* * *$ & G1_RP>S \\
PA & $\leftarrow$ & RP & $\mathbf{- 0 . 2 7 4}$ & 0.021 & -12.888 & $* * *$ & G1_RP>A \\
PA & $\leftarrow$ & PS & $\mathbf{0 . 6 5 4}$ & 0.021 & 30.755 & G1_S $>$ A \\
\hline
\end{tabular}




\section{Discussion and Implication}

A group with a high level of knowledge about nuclear energy and a high level of confidence in that knowledge is more satisfied with nuclear policy than a group without them. In other words, the more people know about nuclear issues, the more positive they are about nuclear policy. The group that only has confidences in fact that they know is more negative toward nuclear power policy. These results suggest that dissatisfaction with nuclear policy is due to lack of confidence and low levels of knowledge about nuclear energy. Moreover, opposition to nuclear energy might arise not only because we do not know nuclear power well, but also because we incorrectly believe we do know it well. Consequently, to increase public satisfaction with nuclear policy, knowledge should be provided to the public based on a more accurate understanding of nuclear energy policy and measures for acquiring it. In such case, a shift in policy orientation could enhance national satisfaction with nuclear energy policy by providing opportunities for education, publicity, or field experience to enable public's proper understanding of nuclear power.

Moreover, the path model's results provided information about a number of variables functioning as mediators; in particular, PD was positively associated with RP, indicating that PD is more fundamental as a core attribute for explaining $R P^{\prime}$ 's variance. Thus, we should pay more serious attention to PD and continue seeking both theoretical and practical insights. Furthermore, in examining cross-cultural differences in the relationship among PD, KC, and PS, the survey should be expanded to include the United States, Japan, and countries in Europe. Comparative research between countries and study on reasons for any differences among them will expand the scope of this research on satisfaction.

Two hypotheses appear insignificant: PD had no significant effect on PED and PS, likely because two factors, PD and PED, have completely different properties. PD is a strong emotional attribute, but PED is a cost-benefit calculation. PED is more reasonable than PD because PED comes from personal experiences of expecting failure or success. Although people might feel close emotionally, they still set the priority over their own interest. Therefore, PD can work independently with PED.

PD does not affect PS directly but through perceived risk. Such a result comes from the subject of PD's position in nuclear power. The main variable with the greatest influence on acceptance of nuclear power is related to proximal causes such as perceived risk, perceived benefit, and trust. Compared to those three variables, PD's direct effect is weak because it plays a remote role in nuclear issues.

\section{Conclusions}

This study mainly analyzed effects PD, KC, RP on "satisfaction with nuclear power policy," finding that PD's effect depended on KC. In addition, PD affects PS and PA through mediation by RP. These results suggest that in communicating with the public, a strategy considering knowledge and RP is necessary for conducting a project to reduce PD. From the perspective of risk communication strategies, it needs actively managing the variables of knowledge and PD.

First, to increase the public's amount of knowledge, increasing accessibility to information on nuclear energy is necessary, especially since nuclear power tends to be kept secret for security purposes. Since secrecy tends to induce suspicion and distrust, it needs actively disclosing information. For this end, information should be posted to online media for easy public access. Moreover, the quality of information should be improved, especially since rumors and misinformation about nuclear power have been circulating, particularly after the Fukushima accident. False news breeds the distrust, consequently lowering public acceptance of nuclear power. A management strategy is needed to monitor false information and improve accurate information. Rather than approaching the public immediately, communication strategies should be established after the public's RP and knowledge level are understood. Finally, this study reveals that knowledge plays a role in the relationship with PD. Thus, knowledge management should consider how close the knowledge of nuclear energy is psychologically to the public's minds. 
Second, to manage PD, it needs fully understanding PD's emotional aspect and developing a public relations strategy that reflects it. Since nuclear technologies have focused on controlling risks because of their complexities, the rational aspect has been emphasized. However, nuclear policy and management has overlooked the emotional aspect. As this study reveals, since the emotional attribute of PD plays an important role in nuclear power's acceptability, it should develop and disseminate the content that emphasizes a positive affective image of nuclear power.

Third, in this study, PD did not directly affect PS and acceptability but affected them through variables of trust, expectation, and perceived risk. This circumstance requires consideration of PD in terms of relationships with other variables. For example, reducing PD can reduce RP, but this reduction does not entirely depend on PD; other factors (e.g., perceived benefit, knowledge, trust) intervened in reduction of RP. This suggests that other factors are active in managing trust, expectation, and RP to amplify the net function of PD.

In that the field of nuclear communication has few studies on PD, this study provides many theoretical and practical implications. Here, the objects of study leave various theoretical themes that should be empirically tested. First, with regard to KC, this study examined whether it plays a role in the relationship between PD and PS. However, PD can play a role in regulating the relationship between KC and PS. Such an inverse relationship must be analyzed empirically. In addition, whether $\mathrm{KC}$ plays roles of mediation and moderation must be analyzed. Finally, how much greater KC's influence is than that of other variables requires comparative analysis.

Also, this study revealed that PD is the remote cause affecting PS and policy acceptability. In future research, first, variables other than TG, PED, and RP that play a mediating role in the relationship between PD and outcome variables should be investigated. Second, although PS and PA are currently configured in a single dimension, they should be constructed in multiple dimensions and how PD affects them should be analyzed. Third, whether this study's focus on the nuclear field can be generalized to other hazardous areas should be analyzed. Fourth, for this study, PD was composed of a single dimension. However, previous studies generally included various sub-dimensions of $P D$, so future research should construct PD multidimensionally and analyze what role each dimension plays.

This study mainly focused on psychological variables. Although psychological factors are important in PS and acceptability, more realistic variables such as benefits and costs to involved groups might be more important. Therefore, evaluating psychological factors according to objective economic, cultural, and social factors is necessary, as is considering their influence on PS and acceptability.

In common with other studies, this one has some limitations. First, the study did not consider subtypes of PD. Second, rather theorizing an entire model, the study took an individual hypothesis-centered approach. Third, generalizing the research results would be difficult since we used data collected only from Korea. Even with these limitations, however, the research can provide meaningful insights for countries with similar nuclear energy issues.

Author Contributions: Conceptualization, Methodology, and Writing-Review and Editing, B.J.K.; Formal Analysis and Writing-Original Draft Preparation, Project Administration, S.K. Both authors have read and agreed to the published version of the manuscript.

Funding: This work was supported by the Ministry of Education of the Republic of Korea and the National Research Foundation of Korea (NRF-2021S1A5C2A02087244). This research received financial support by Kookmin University.

Institutional Review Board Statement: Not applicable.

Informed Consent Statement: Informed consent was obtained from all subjects involved in the study. 
Data Availability Statement: Data presented in this study are available on request from the corresponding author. Data are not publicly available due to regulations and guidelines of data open policy according to the National Research Foundation of Korea.

Acknowledgments: This work was supported by the Ministry of Education of the Republic of Korea and the National Research Foundation of Korea (NRF-2021S1A5C2A02087244). This work was supported by Kookmin University.

Conflicts of Interest: The authors declare no conflict of interest.

\section{References}

1. Ryu, Y.J.; Kim, S. The study of the effects of different message sources and direction on receiver's attitude change about nuclear power energy. J. Saf. Crisis Manag. 2015, 11, 125-146. [CrossRef]

2. Rorhmann, O.; Renn, B. Cross-Cultural Risk Perception; Kluwer Publishers: Dordrecht, The Netherlands, 2000.

3. Tanaka, Y. Major psychological factors determining public acceptance of the siting of nuclear facilities. J. Appl. Psychol. 2004, 34, 1147-1165. [CrossRef]

4. Flynn, J.; Burns, W.; Mertz, C.K.; Slovic, P. Trust as a determinant of opposition to a high-level radioactive waste repository: Analysis of a structural model. Risk Anal. 1992, 12, 417-429. [CrossRef]

5. Visschers, V.H.M.; Siegrist, M. Fair play in energy policy decisions: Procedural fairness, outcome fairness and acceptance of the decision to rebuild nuclear power plants. Energy Policy 2012, 46, 292-300. [CrossRef]

6. Kim, S. The Structure of Risk Perception and Public Policy Implications. In Proceedings of the KNEA Workshop, Daejeon, Korea, 1 June 2017; pp. 1-19.

7. Liberman, N.; Trope, Y. The role of feasibility and desirability considerations in near and instant future decisions: A test of temporal construal theory. J. Pers. Soc. Psychol. 1998, 75, 5-18. [CrossRef]

8. Chang, H.; Zhang, L.; Xie, G.X. Message framing in green advertising: The effect of construal level and consumer environmental concern. Int. J. Advert. 2015, 34, 158-176. [CrossRef]

9. Jeon, Y.; Mok, J.W.; Kim, B.J. The influences of risk perception and trust in government on nuclear energy policy compliance and satisfaction: Applying the Expectancy Disconfirmation Model. Korean J. Policy Anal. Eval. 2016, 26, 85-110.

10. Park, C.; Kim, S. The role of knowledge in acceptance of nuclear power: A focus on objective and subjective knowledge. Korean J. Public Admin. 2015, 53, 117-150.

11. Levi, D.J.; Holder, E.E. Psychological factors in the nuclear power controversy. Polit. Psychol. 1988, 9, 445-457. [CrossRef]

12. Stoutenborough, J.W.; Sturgess, S.G.; Vedlitz, A. Knowledge, risk, and policy support: Public perception of nuclear power. Energy Policy 2013, 62, 176-184. [CrossRef]

13. Lim, C.; Kim, S. The study on negative effect of nuclear corruption scandal and the mechanism of trust. Korean J. Public Admin. 2014, 23, 131-159.

14. Pillai, K.; Goldsmith, R. Knowledge calibration and knowledge management. Encycl. Knowl. Manag. $2010,1,497-505$.

15. Pillai, K.G.; Hofacker, C. Calibration of consumer knowledge of the web. Int. J. Res. Mark. 2007, 24, 254-267. [CrossRef]

16. Alba, J.; Hutchinson, J. Knowledge calibration: What consumers know and what they think they know. J. Consum. Res. 2000, 27, 123-156. [CrossRef]

17. Kuklinski, J.H.; Metlay, D.S.; Kay, W.D. Citizen knowledge and choices on the complex issue of nuclear energy. Am. J. Polit. Sci. 1986, 26, 615-642. [CrossRef]

18. Brown, J.M.; White, H.M. The public's understanding of radiation and nuclear waste. J. Radiol. Prot. 1987, 7, 61-70. [CrossRef]

19. Katsuya, T. Difference in the information of attitude toward nuclear power. Polit. Psychol. 2002, 23, 191-203. [CrossRef]

20. Sjöberg, L.; Drottz-Sjöberg, B. Knowledge and risk perception among nuclear power plant employees. Risk Anal. 1991, 11, 607-618. [CrossRef]

21. Siegrist, M.; Cvetkovich, G. Perception of hazards: The role of social trust and knowledge. Risk Anal. 2000, 20, 713-719. [CrossRef]

22. Berger, I.E.; Ratchfordb, B.T.; Haines, G.H., Jr. Subjective product knowledge as a moderator of the relationship between attitudes and purchase intentions for a durable product. J. Econ. Psychol. 1994, 15, 301-314. [CrossRef]

23. House, L.; Lusk, J.; Jaeger, S.; Traill, W.B.; Moore, M.; Valli, C.; Morrow, B.; Yee, W. Objective and subjective knowledge: Impacts on consumer demand for genetically modified foods in the United States and the European Union. AgBioForum 2004, 7, 113-123.

24. Tuu, H.H.; Olsen, S.O.; Linh, P.T.T. The moderator effects of perceived risk, objective knowledge and certainty in the satisfaction? loyalty relationship. J. Consum. Mark. 2011, 28, 363-375. [CrossRef]

25. Selnes, F.; Gronhaug, K. Subjective and objective measures of product knowledge contrasted. Adv. Consum. Res. 1986, 13, 67-71.

26. Massara, F.; Severino, F. Psychological distance in the heritage experience. Ann. Tour. Res. 2013, 42, 108-129. [CrossRef]

27. Liu, W.; Zeng, L.; Wang, Q. Psychological distance toward air pollution and purchase intention for new energy vehicles: An investigation in China. Front. Psychol. 2021, 12, 569115. [CrossRef] [PubMed]

28. Tan, H.; Wong-Parodi, G.; Xu, J. Not under my backyard? Psychological distance, local acceptance, and shale gas development in China. Energy Res. Soc. Sci. 2020, 61, 101336. [CrossRef]

29. Ng, S.I.; Lee, J.A.; Soutar, G.N. Tourists' intention to visit a country: The impact of cultural distance. Tour. Manag. 2007, 28, 1497-1506. [CrossRef] 
30. Ankomah, P.K.; Crompton, J.L.; Baker, D. Influence of cognitive distance in vacation choice. Ann. Tour. Res. 1996, 23, 138-150. [CrossRef]

31. MacKay, K.J.; Fesenmaier, D.R. Pictorial element of destination in image formation. Ann. Tour. Res. 1997, 24, 557-565. [CrossRef]

32. Tasci, A.D.A. The missing link in the loop of movies, destination, image, and tourism behavior? J. Travel Res. $2009,47,494-507$. [CrossRef]

33. Putnam, R. Bowling alone; America's declining social capital. J. Democr. 1995, 6, 65-87. [CrossRef]

34. Norris, P. Digital Divide: Civic Engagement, Information Poverty and the Internet; Cambridge University Press: New York, NY, USA, 2001.

35. Wang, J. Trust and nuclear energy policy acceptance. Korean J. Policy Stud. 2013, 22, 235-266.

36. Lægreid, P.; Christensen, T. Trust in government: The relative importance of service satisfaction, political factors, and demography. Public Perfor. Manag. Rev. 2005, 28, 679-690.

37. Oliver, R.L. A cognitive model of the antecedents and consequences of satisfaction decisions. J. Mark. Res. 1980, 17, 460-469. [CrossRef]

38. Van Ryzin, G.G. Expectations, performance, and citizen satisfaction with urban service. J. Policy Anal. Manag. 2004, 23, 433-448. [CrossRef]

39. Park, S.; Hwang, D. An Analysis of policy satisfaction using the expectancy disconfirmation model. Korean J. Policy Stud. 2010, 25, 47-67.

40. Maglio, S.J. Psychological distance in consumer psychology: Consequences and antecedents. Consum. Psychol. Rev. 2020, 3, 108-125. [CrossRef]

41. Darke, P.R.; Brady, M.K.; Benedicktus, R.L.; Wilson, A.E. Feeling close from afar: The role of psychological distance in offsetting distrust in unfamiliar online retailers. J. Ret. 2016, 92, 287-299. [CrossRef]

42. Packard, G.; Moore, S.G.; McFerran, B. (I'm) Happy to help (You): The impact of personal pronoun use in customer-firm interactions. J. Mark. Res. 2018, 55, 541-555. [CrossRef]

43. Zheng, L.; Miao, M.; Gan, Y. Perceived control buffers the effects of the COVID-19 Pandemic on general health and life satisfaction: The mediating role of psychological distance. Appl. Psychol. Health Well Being 2020, 2, 1095-1114. [CrossRef]

44. Spence, A.; Poortinga, W.; Pidgeon, N. The psychological distance of climate change. Risk Anal. 2012, 32, 957-972. [CrossRef] [PubMed]

45. Chu, H.; Yang, J.Z. Risk or Efficacy? How psychological distance influences climate change engagement. Risk Anal. 2020, 40, 758-770. [CrossRef]

46. Kim, S. Exploring attitude change in acceptance of nuclear power: The use of the conditional stimuli questions. Korean Rev. Crisis Emerg. Manag. 2015, 11, 295-321. [CrossRef]

47. Kasperson, J.X.; Kasperson, R.E. Global Environmental Risk; Routledge: Abingdon, UK, 2013.

48. Chen, C.W.S.; Lee, S.; Dong, M.C.; Taniguchi, M. What factors drive the satisfaction of citizens with governments' responses to COVID-19? Int. J. Infect Dis. 2021, 102, 327-331. [CrossRef] [PubMed]

49. Pytlik Zillig, L.M.; Hutchens, M.J.; Muhlberger, P.; Gonzalez, F.J.; Tomkins, A.J. Policy Acceptance. In Deliberative Public Engagement with Science; Springer Briefs in Psychology; Springer: Cham, Switzerland, 2018. [CrossRef]

50. Hu, L.; Bentler, P.M. Cutoff criteria for fit indexes in covariance structure analysis: Conventional criteria versus new alternatives. Struct. Equ. Model. 1999, 6, 1-55. [CrossRef] 